\title{
ANTROPOLOGIA E POLÍTICA
}

\section{Karina Kuschnir}

A abordagem da política pela antropologia pode ser definida de uma forma simples: explicar como os atores sociais compreendem e experimentam a política, isto é, como significam os objetos e as práticas relacionadas ao mundo da política. A compreensão de grupos específicos, em circunstâncias particulares, leva a comparações e diálogos com a literatura sobre contextos sociais mais amplos.

Embora aparentemente simples, trata-se de uma proposta complexa de ser executada e que implica pelo menos dois pressupostos. O primeiro, de que a sociedade é heterogênea, formada por redes sociais que sustentam e possibilitam múltiplas percepções da realidade. O segundo, de que o "mundo da política" não é um dado $a$ priori, mas precisa ser investigado e definido a partir das formulações e dos comportamentos de atores sociais e de contextos particulares.

O interesse da antropologia pela política existe desde os primórdios da disciplina, uma vez que o estudo de sociedades e relações sociais é estreitamente ligado à temática das relações de poder. No contexto da tradição evolucionista, que marcou a fase inicial da antropologia, o foco recaía sobre as formas e os sistemas de poder em sociedades "primitivas", cujas características deveriam ser comparadas e classificadas em relação ao sistema político das sociedades modernas, consideradas mais "evoluídas". Propunha-se, então, uma linha evolutiva das formas de organização política, que começava com a "horda primitiva" e chegava ao Estado moderno. Nessa época, entre o final do século XIX e o início da década de 1920, a grande maioria dos estudos antropológicos não tinha a política como tema central de interesse, nem a antropologia política era pensada ou formalizada como uma subárea de estudos.

Com o avanço da tradição estrutural-funcionalista britânica, no entanto, a política ganhou espaço, sobretudo nas etnografias realizadas no contexto colonial anglo-africano. Muitos desses 
estudos buscavam entender a organização social de grupos e etnias sem a presença de um sistema político formal, isto é, sem Estado. É nessa direção que surgem as reflexões sobre a importância dos sistemas de parentesco para a hierarquia e a coesão sociais. Tendo como referência inicial Radcliffe-Brown, sucederam-se autores como Evans-Pritchard, Meyer Fortes, Max Gluckman, Edmund Leach e Victor Turner, entre outros. Alguns dos textos fundamentais da então recém-nomeada "antropologia política" foram produzidos nesse contexto, como a coletânea African political systems (Fortes e Evans-Pritchard, [1940] 1961) e a monografia Os Nuer (EvansPritchard, [1940] 1978). Essa abordagem, por sua vez, também gerou críticas. A definição de poder teria se tornado tão ampla que poderia ser encontrada em qualquer situação social, englobando literalmente todos os temas da disciplina (Vincent, 2002). Mas é nessa fase que se consolidou institucionalmente o campo de uma antropologia política (Easton, 1959). É fundamental ressalvar que, embora dialogando entre si com mais ou menos freqüência, esses antropólogos não produziram em absoluto abordagens homogêneas da política. Se numa primeira etapa foi dada maior ênfase aos aspectos de coesão e equilíbrio social, à medida que avançamos no tempo, observamos uma maior preocupação com as transformações sociais, discutindo as relações de poder no tempo e no espaço, a partir de temáticas relacionadas a conflitos, rituais, mitos, identidades, status, representações e práticas.

A partir da década de 1950, principalmente depois do clássico Sistemas políticos da Alta Birmânia, de Edmund Leach ([1954] 1996), desenvolve-se uma nova fase no campo da antropologia política, com o afastamento do cânone tradicional e a pulverização de problemas teóricos e temas de pesquisa, cujo alcance foge ao âmbito deste texto. Entretanto, há um certo consenso de que esses novos campos são fruto sobretudo do enfrentamento dos desafios impostos por uma conjuntura mundial na qual convivem forças políticas e culturais em diversos níveis como comunismo, capitalismo, colonialismo e movimentos sociais de diversos tipos. Entre estes, a área dos estudos feministas e dos movimentos anticolonialistas ganhou destaque por sua impor- tante contribuição para a reflexão em torno do poder (Vincent, 2002).

No contexto brasileiro, desenvolveu-se, na década de 1990, um conjunto de trabalhos autodenominados antropologia da politica, que tiveram sua institucionalização mais importante no Núcleo de Antropologia da Política (NuAP), sediado no Museu Nacional da UFRJ, mas envolvendo grupos em outras universidades federais, como as de Brasília, Ceará e Rio Grande do Sul, entre outras. O objetivo do NuAP, como definiu Peirano (1998), era partir da "suposição básica de que a categoria política é sempre etnográfica". Ao investigar a política legitimada pelos padrões ocidentais modernos, "deslegitimando pretensões essencialistas, sociocêntricas e conformistas", revela-se que a própria percepção da "política" como uma esfera social à parte de outras esferas é produto dessa ideologia moderna. No caso brasileiro, alerta Peirano, o antropólogo enfrentaria uma "combinação complexa" de universalismo científico e ideologia nacional de moldes "holistas".

Isso tem sido observado em muitos estudos empíricos, desde o clássico Coronelismo, enxada e voto (Leal, 1948) até as recentes etnografias e coletâneas publicadas no âmbito do NuAP (Palmeira e Goldman, 1996; Barreira e Palmeira, 1998; Heredia, Teixeira e Barreira, 2002; Palmeira e Barreira, 2006). A política é entendida, aqui, principalmente como um meio de acesso aos recursos públicos, no qual o político atua como mediador entre comunidades locais e diversos níveis de poder. Esse fluxo de trocas é regulado pelas obrigações de dar, receber e retribuir, o que o antropólogo Marcel Mauss ([1924] 1974) chamou de "lógica da dádiva", e cujo princípio fundamental está no comprometimento social daqueles que trocam para além das coisas trocadas.

As pessoas que participam dessas redes, seja como eleitores, seja como políticos, nunca concordariam com os acadêmicos que consideram suas ações um mero "clientelismo". Do ponto de vista "nativo", os políticos não estão "privatizando bens públicos" (para usar uma definição clássica de clientelismo); ao contrário, os políticos estão dando acesso a bens e serviços públicos a pessoas que não os teriam de outra forma. Nesse contexto, a palavra "público" não significa "recursos que pertencem a todos", mas "recursos monopoliza- 
dos pelas elites políticas e econômicas". Ou seja, pessoas "ordinárias" - de estratos inferiores da sociedade - não participariam dessa definição de "público". Por isso mesmo, o acesso às fontes públicas de bens e serviços precisa ser intermediado pelo político e é visto como um bem extraordinário, "que não tem preço".

No entanto, essa rede não se constitui apenas pelo acesso e intermediação de recursos públicos. A distribuição de bens e serviços em locais de "atendimento", como centros de assistência social ou escritórios políticos, é prática corrente. Para manter esse tipo de serviço, o político precisa manter fortes laços com empresários ou grupos economicamente favorecidos que lhe forneçam dinheiro ou mercadorias demandados pela comunidade. Essa ajuda externa é retribuída, por sua vez, na forma de alvarás, licenças, anistia de multas e outros benefícios diversos. Pode também, sem dúvida, em certos casos, caracterizar-se como corrupção pura e simples.

Como se coloca, então, a antropologia da política ante a questão da democracia? Se nos basearmos nos seus princípios conceituais, relações de troca do tipo acima mencionadas são um grande desserviço. Entretanto, como intelectuais, temos que evitar que nosso desejo de melhorar a qualidade da democracia interfira na forma como coletamos e interpretamos os dados de pesquisa. Senão, ficaremos perpetuamente rotulando as pessoas em vez de tentar compreendêlas. Seguindo a proposta de Peirano (1998), esses mesmos rótulos operam segundo lógicas de poder da academia ou até lógicas de poder mais amplas. Assim, o mesmo fenômeno classificado como "máquina política", nos Estados Unidos, torna-se "clientelismo", na América Latina, ou "serviços aos eleitores", no Reino Unido (PosadaCarbó, 2005).

Categorias como "mandonismo", "coronelismo", "clientelismo", entre outras, trazem embutidas a idéia de que as nossas práticas políticas são imperfeitas, atrasadas ou inferiores. Trata-se de classificações que tomam por base o princípio de que as sociedades modernas devem estar comprometidas com os princípios democráticos universais inspirados nas experiências européia e norte-americana. Desse ponto de vista, o clientelismo será sempre visto como sintoma de nosso estágio de "subdesenvolvimento" e, portanto, um problema para a "modernização" da política.

Seguindo em outra direção, podemos tomar o "clientelismo" como expressão de valores culturais que privilegiam as relações sociais entre pessoas, por oposição às relações entre indivíduos, no sentido que Roberto Da Matta (1979) emprestou ao termo. Isto é, trata-se de trocas e relações sociais que envolvem noções como honra, gratidão e dívida moral. Em muitos casos, isso ajuda também a perceber que as relações de troca empiricamente observadas não se constituem numa esfera "política" à parte, muito menos são a principal fonte de recursos da população. Tanto é assim que muitos dos bens doados por políticos são itens aparentemente supérfluos, como perucas, camisas para times de futebol, brinquedos, latas de tinta etc.

Para a antropologia, é preciso investigar tais trocas dentro do contexto etnográfico em que ocorrem, buscando a compreensão das relações sociais envolvidas. Em muitos casos, essa compreensão é fundamental para percebermos que a política opera com valores da sociedade mais abrangente, tradicionalmente associados a outras esferas da vida social, como família e religião, mas considerados ilegítimos quando operados na esfera política. Isso não quer dizer, obviamente, que se queira justificar nem defender essas práticas - cumpre, antes de tudo, compreendê-las.

Onde ficaria, então, a responsabilidade e a contribuição da antropologia para com os princípios da democracia representativa e o aperfeiçoamento das suas instituições?

Como afirmou Abélès (1997), a antropologia não tem como objetivo criticar as práticas políticas, mas entender a maneira pela qual as relações de poder emergem numa situação determinada, adquirindo significado para os atores sociais. Parte sempre do pressuposto de que a "democracia" é um modelo teórico, e que, portanto, não existe de forma pura. Questionar conceitos como "clientelismo" é deixar de tomar esse modelo como ponto de partida; é não considerar universais termos como, por exemplo, "individualismo", "representação" e "domínio público"; é, finalmente, perceber que o universalismo é um valor inspirado no paradigma da modernização, na crença de que a imparcialidade e a objetivi- 
dade devem prevalecer sobre as emoções e a subjetividade (como as que estão presentes nas relações baseadas na honra e na dádiva).

A abordagem antropológica privilegia técnicas de pesquisa qualitativas, voltadas para a realização de trabalho de campo com observação participante e entrevistas em profundidade, freqüentemente produzindo "estudos de casos". No entanto, o antropólogo não ignora que as práticas e as representações observadas estão inseridas numa sociedade maior, num sistema político formal, com instituições de larga escala. Nesse esforço, a antropologia de um modo geral oscila entre sua fidelidade ao particular e a necessidade de produzir generalizações (Lewellen, 1992). Por isso, é fundamental que se estabeleça um diálogo com outras disciplinas, como a história, a ciência política, a sociologia, a lingüística e a comunicação. É a partir de abordagens multi e interdisciplinares e da adoção de uma perspectiva comparativa que se pode chegar a compreender não só as representações e as práticas da política num grupo específico, mas também as relações desse material etnográfico com a sociedade mais ampla.

A antropologia pode contribuir nesse debate porque sua principal tarefa é estudar não o que a política deve ser, mas o que ela é para um determinado grupo, em um contexto histórico e social específico. Compreender, "do ponto de vista do nativo", práticas muitas vezes diferentes daquelas que idealizamos pode gerar incômodo, intelectual ou cívico, mas um incômodo necessário, pois, como disse Geertz, "se quiséssemos verdades caseiras, deveríamos ter ficado em casa" (2001, p. 67).

\section{BIBLIOGRAFIA}

ABÉLÈS, M. (1997). "Political anthropology: new challenges, new aims", International Social Science Journal, 153: 319-332.

BARREIRA, I. \& PALMEIRA, M. (orgs.). 1998, Candidatos e candidaturas: enredos da campanha eleitoral no Brasil. São Paulo, Annablume.
DA MATTA, R. (1979), Carnavais, malandros $e$ heróis. Rio de Janeiro, Zahar.

EASTON, D. (1959), "Political anthropology". Biennial Review of Anthropology, Stanford University Press.

EVANS-PRITCHARD, E. ([1940] 1978), Os Nuer. São Paulo, Perspectiva.

FORTES, M. \& EVANS-PRITCHARD, E. (orgs.). ([1940] 1961), African political systems. Londres, Oxford University Press.

GEERTZ, C. (2001), Nova luz sobre a antropologia. Rio de Janeiro, Zahar.

HEREDIA, B.; TEIXEIRA, C. \& BARREIRA, I. (orgs.). (2002), Como se fazem eleições no Brasil. Rio de Janeiro, RelumeDumará.

LEACH, E. ([1954] (1996), Sistemas políticos da Alta Birmânia. São Paulo, Edusp.

LEAL, V. (1948), Coronelismo, enxada e voto. Rio de Janeiro, Forense.

LEWELLEN, T. (1992). Political anthropology: an introduction. Westport/Londres, Bergin \& Garvey.

MAUSS, M. ([1924] (1974), "Ensaio sobre a dádiva, forma e razão da troca nas sociedades arcaicas", in Mauss, M. Sociologia e antropologia. São Paulo, EPU, vol. 2, pp. 37-184.

PALMEIRA, M. \& BARREIRA, C. (orgs.). (2006), Política no Brasil: visões de antropologia. Rio de Janeiro, Relume Dumará/NuAP/UFRJ.

PALMEIRA, M. \& GOLDMAN, M. (orgs.). (1996), Antropologia, voto e representação política. Rio de Janeiro, Contra Capa.

PEIRANO, M. (1998), "Antropologia política, ciência política e antropologia da política", in ____ Três Ensaios Breves. Brasília, UnB, "Série Antropologia", n. 230, pp. $17-29$.

POSADA-CARBÓ, E. (2005), Comunicação oral realizada no Seminário "Political clientelism in contemporary democracies: the case of Brazil in comparative and interdisciplinary perspective". Oxford, 
University of Oxford (comunicação oral).

VINCENT, J. (2002), The anthropology of politics: a reader in ethnography, theory, and critique. Malden, Mass./Oxford, Blackwell. 